\title{
Lessons Learned: Teaching In-Person During the COVID-19 Pandemic
}

\author{
Alvin $\operatorname{Tran}^{1 *}$, Robin L. Kerkstra ${ }^{2}$, Sarah Logan Gardocki ${ }^{1}$ and Savannah C. Papuga ${ }^{2}$ \\ ${ }^{1}$ Department of Health Administration and Policy, School of Health Sciences, University of New Haven, West Haven, CT, \\ United States, ${ }^{2}$ Department of Allied Health, School of Health Sciences, University of New Haven, West Haven, CT, United States
}

OPEN ACCESS

Edited by:

Adrian Castro-Lopez,

University of Oviedo, Spain

Reviewed by:

Dhiraj Indana,

Stanford University, United States

Naiara Berasategi,

University of the Basque Country,

Spain

*Correspondence:

Alvin Tran

atran@newhaven.edu

Specialty section:

This article was submitted to

Higher Education,

a section of the journal

Frontiers in Education

Received: 03 April 2021 Accepted: 10 May 2021

Published: 26 May 2021

Citation:

Tran A, Kerkstra RL, Gardocki SL and Papuga SC (2021) Lessons Learned: Teaching In-Person During the COVID-

19 Pandemic.

Front. Educ. 6:690646.

doi: $10.3389 /$ feduc.2021.690646
For the Fall 2020 semester, the University of New Haven (UNewHaven) joined over a third of colleges and universities across the country in offering in-person courses and reopening its campus. Allowing the campus community to safely return was a challenging endeavor, particularly for those at the University's School of Health Sciences, which offers both nonclinical and clinical courses. In order to create learning environments that adhered to continuously-changing guidelines, our team at the School of Health Sciences was forced to develop and implement innovative strategies. In this article, we share our experiences in fulfilling our roles as faculty, staff, and students at a School of Health Sciences offering inperson, non-clinical and clinical courses during the COVID-19 pandemic. We reflect upon our challenges and share the lessons learned, which we hope will serve as guidance for our collective community in higher education, including those working within schools of public health and health sciences. Our lessons learned are presented in following three themes: 1) preparation for in-person classes; 2) the emotional state of faculty, staff, and students; and 3) innovative practices. Should colleges and universities ever find themselves in similar, yet unprecedented times, our lessons and recommendations may serve as a starting point to assist them in navigating through such tumultuous moments.

Keywords: COVID-19, pandemic, health sciences, dental hygiene, clinical, didactic, education

\section{INTRODUCTION}

In August 2020, the University of New Haven (UNewHaven) joined over a third of colleges and universities in the United States (U.S.) in fully reopening its campus (Here's Our List of Colleges' Reopening Models, 2020). Based in West Haven, Connecticut, UNewHaven is a four-year institution that serves nearly 7,000 undergraduate and graduate students and is comprised of five colleges, including the School of Health Sciences (University of New Haven, 2021). The process of reopening during the COVID-19 pandemic included the requirement of "return to campus COVID-19 tests" and ongoing randomized testing for all returning students, faculty, and staff.

Opening college campuses during the pandemic was both a challenging and controversial decision that was met with scrutiny (Sorrell, 2020; Yamey and Walensky, 2020). Critics raised concerns over the health and safety of all individuals working on campuses-from students, to faculty, and staff-as there are no re-opening strategies that are risk-free (Wrighton and Lawrence, 2020). Furthermore, young adults represented a large proportion of new COVID-19 infections between June through August 2020 (Boehmer et al., 2020). However, many colleges and universities opted to reopen in light of financial pressures, demands from students to offer inperson courses, and challenges with offering clinical and lab-based coursework in a virtual format (Higgins-Dunn, 2020; Quintana, 2020; Wrighton and Lawrence, 2020; Yamey and Walensky, 2020). 
The task of offering on-ground (aka in-person) courses has been challenging for many institutions, as COVID-19 outbreaks emerged on many campuses (Tracking the Coronavirus at U.S. Colleges and Universities, 2020). According to a survey of 1,900 colleges and universities, the New York Times estimated 397,000 cases of COVID-19 and at least 90 deaths have occurred due to possible infections originating on campuses in the U.S. since the beginning of the pandemic (Tracking the Coronavirus at U.S. Colleges and Universities, 2020). Less than a week after opening its campus to students in August 2020, the University of North Carolina at Chapel Hill closed following a spike in COVID-19 cases (Treisman, 2020). Other colleges and universities across the country also experienced similar outbreaks shortly after opening (Nadworny, 2020).

At UNewHaven, university officials, guided by state and federal recommendations, including the Centers for Disease Control and Prevention's (CDC) COVID-19 testing guidance for colleges (Centers for Disease Control and Prevention, 2020; Redden, 2020), implemented a number of COVID-19 directives, including a campus-wide mask mandate. Students enrolled in on-ground courses and their instructors were required to wear protective masks and were situated at least six feet apart. Eating and drinking were prohibited in all classrooms, although students and instructors were allowed to take breaks to snack and consume beverages in designated locations.

A key factor for reopening UNewHaven was to continue its clinic-based courses. The School of Health Sciences offers a number of interdisciplinary undergraduate and graduate programs, including its accredited dental hygiene program, which generally provides students with patient interaction (School of Health Sciences, 2020). Table 1. summarizes the demographics of students enrolled in the UNewHaven School of Health Sciences in Fall 2020, including clinical vs. non-clinical students. Reopening college campuses is arguably essential for students in the health professions that involve clinical training, such as medicine, dentistry, and related fields. For healthcare students, studies suggest hands-on and real life experiences are associated with increased preparedness (Burford, Whittle, and Vance, 2014). Acknowledging the high risk of infection, many have called for the continuation of in-person clinical programs as they will ensure that healthcare students will graduate on time, particularly during a period when they are in high-demand (MedEd Collaborative, 2020).

Here we reflect upon our experiences during the Fall 2020 semester at an academic institution, that chose to open and offer in-person, clinical and non-clinical courses during the COVID19 pandemic. We share our unique perspectives as faculty, staff, and students with hopes that individuals at other academic institutions will learn from our experiences, including our successes and challenges as members of the UNewHaven's School of Health Sciences. We aim to assist others in successfully navigating through this ongoing pandemic, as well as future public health threats, with the lessons we learned based on the following themes: 1) preparation for in-person classes; 2) the emotional state of faculty, staff, and students; and 3) innovative practices.
TABLE 1 | Sample demographics.

\begin{tabular}{|c|c|}
\hline Characteristic & $\begin{array}{c}\text { Total } N=619(100.0 \%) n \\
(\%)\end{array}$ \\
\hline \multicolumn{2}{|l|}{ Sex } \\
\hline Female & 491 (79.3) \\
\hline Male & $128(20.7)$ \\
\hline \multicolumn{2}{|l|}{ Race/Ethnicity } \\
\hline Asian or pacific islander & $35(5.6)$ \\
\hline Black or African American & 99 (16.0) \\
\hline Hispanic & $77(12.4)$ \\
\hline Non-residential alien & $61(9.9)$ \\
\hline Other & $22(3.6)$ \\
\hline White & $325(52.5)$ \\
\hline \multicolumn{2}{|l|}{ Grade level } \\
\hline Graduate & $196(31.7)$ \\
\hline Undergraduate & $423(68.3)$ \\
\hline \multicolumn{2}{|l|}{ Clinical status } \\
\hline Clinical program ${ }^{a}$ & $233(37.6)$ \\
\hline Non-clinical program & $386(62.4)$ \\
\hline
\end{tabular}

a Includes students enrolled in the dental hygiene or paramedicine undergraduate programs. All other majors are non-clinical programs.

\section{PREPARATION FOR IN-PERSON CLASSES}

With the increasing prevalence of COVID-19 in 2020, many universities were forced to move to online education. Clinical and didactic instruction also changed drastically due to social distancing and safety protocols for in-person classes, including medical training programs that include pre-clerkships and clerkships (Guadix et al., 2020). Adapting to constantly changing recommendations from health and government officials to keep members of our university safe demanded flexibility. Special challenges immediately presented themselves to meet the evolving state and CDC guidelines (Centers for Disease Control and Prevention, 2021) for in-person education.

One challenge for didactic teaching resources was the limited classroom space allowing for socially distanced teaching and learning by providing a six-foot bubble around students and the instruction area. Classrooms were created from nontraditional spaces on campus (e.g., university-affiliated church, athletic studios) in order to allow socially distanced in-person classes. These non-traditional spaces presented challenges as many were only partially outfitted with the technology needed for instruction (e.g., the university-affiliated church was not equipped with adequate desktops needed for clinic-based courses).

Managing clinically-based programs also raised challenges. For example, students in our dental hygiene program must meet specific patient contact hours as part of key accreditation requirements. However, accessing patients, who were generally from the surrounding community, was highly restricted due to concerns of COVID-19 transmission. Additionally, external service learning sites (e.g., community partner clinics) were unable to host students for on-site clinical experiences. Many students were also placed into quarantine due to possible exposure to COVID-19-another factor that reduced their inperson training. To meet patient contact accreditation challenges, the development of online coursework for dental hygiene 
students was necessary. Best practices for online clinical coursework included developing detailed student learning outcomes and restructuring rubrics to demonstrate learning with case studies in place of some patient contact hours. High impact practices including group work using Zoom breakout rooms kept students engaged.

We also experienced communication challenges due to the university-wide requirements to wear masks on campus. To meet the six-foot distancing requirement, many classrooms were held in large rooms and lecture halls, which presented communication challenges between faculty and their students. Individuals with hearing loss were also at a disadvantage, as the mask mandate prevented them from being able to read lips and other nonverbal facial cues. However, these mitigation strategies proved successful, as no COVID-19 infection spread was traced back to classrooms or other instructional areas.

From a faculty perspective, lecturing often required shouting or louder talking voices in order to be heard in larger rooms that were not equipped with microphones and other essential technology. This communication barrier presented difficulties in maintaining students' engagement because they often could not hear or understand the lecturer.

Reflecting upon our past challenges, we believe adaptation, flexibility, and planning for future incidents, including pandemics, is essential. In anticipation for other impending public health threats, academic institutions should ensure that non-traditional classrooms (e.g., university-affiliated church, athletic studios) can be easily equipped with essential technology. Clinically-based programs have developed alternative teaching strategies to help students meet accreditation and knowledge milestones. Developing and maintaining a secondary strategy for teaching clinical skills during such emergencies should remain a part of the curriculum. Finally, using classroom integrated microphones or portable microphones may address communication challenges in nontraditional classrooms.

\section{EMOTIONAL STATE OF FACULTY, STAFF, AND STUDENTS}

\section{Faculty and Staff}

"We cannot help but impute emotions to the behaviors of others, and constantly infer not only what others are feeling but also why they feel that way" (Spunt and Adolphs, 2019). This quote accurately describes the basis of the emotional state of UNewHaven School of Health Sciences faculty while teaching during the pandemic. The emotional state refers to emotions and behaviors which are related to a psychological and physiological state (Kim et al., 2013). The evolution of the pandemic has shocked educators in higher education forcing the reevaluation of best practices in every area of course delivery. One of the common themes among faculty following teaching in-person courses during the pandemic was emotional, mental, and physical exhaustion. Emotional exhaustion is frequently the focus of educational research related to educator burnout (Maslach et al., 2001). Emotional exhaustion, cynicism, and inefficacy are the result of prolonged interpersonal and emotional stressors within education (Chang, 2009; Goetz et al., 2015; Arens and Morin, 2016; Taxer et al., 2019). At the School of Health Sciences, faculty frequently experienced isolation from colleagues, anxiety, and expectations to meet new teaching standards through in-person, hybrid, and online learning modalities. Uncertainty regarding job security, student satisfaction with teaching, and day-to-day changes with teaching recommendations due to the pandemic contributed to burnout. Furthermore, faculty did not receive training to effectively cope and reduce stress. Such concerns around mental health among of members of university and college campuses during the pandemic continue to be documented, with researchers attributing such health consequences to increased workload related to adapting to changes in laboratory and practical activities (Anderton et al., 2021).

Non-teaching staff, who often provide various forms of support to students, also experienced heightened anxiety around job security, as they were among the groups within higher education most affected by furloughs (Bauman, 2020). Additionally, staff became reluctant to express their health and safety concerns, even as they were tasked with additional roles and responsibilities (Anderson, 2020).

Adding to the emotional state, faculty and staff were forced to address COVID-19 induced situations hastily. As schools begin to close, many faculty and staff with children found themselves without adequate childcare and were forced to innovatively juggle work and homelife responsibilities. Additionally, faculty and staff were concerned with students' emotional and mental health, as many were often distracted and lacked focus in class.

Developing strategies to maintain and improve the emotional, mental, and physical health for faculty and staff should not be ignored. Offering virtual services such as medical counseling, mental health counseling, and opportunities to join virtual exercise classes for physical health could help to ward off mental and physical exhaustion (Ruegsegger and Booth, 2018). Training faculty and staff to identify signs of anxiety and depression among individuals will assist in recognizing and meeting the needs of students and colleagues. Additionally, generating positive thinking and feeling for educators associated with work-related demands can help manage exhaustion resulting from increased workload and addressing students' needs (Nordhall et al., 2020).

\section{Students}

Concerns over students' emotional and mental health grew as a result of the ongoing pandemic and its resulting public health measures (e.g., stay-at-home orders). Students' motivation, concentration, and social interactions remained crucial factors for their overall success (Son et al., 2020). As a university that offered in-person courses, UNewHaven students were frequently placed into quarantine or isolation for varying periods of time due to COVID-19 exposure. Being placed into quarantine due to possible exposure to COVID-19, or being isolated due to confirmed infection, was tolling on students' emotional, physical, and mental well-being and contributed to burnout. Often referred to as "COVID brain fog," students often found 
themselves feeling sluggish, unable to concentrate, and battling with the stigma of needing to stay on top of their course work regardless of their physical or mental health status (Budson, 2021). Many School of Health Sciences students reported feeling defeated, lacking motivation, and anxious as they worry about the pandemic and their own mental fatigue.

Universities should strategize how to promote and maintain students' overall health-physically, mentally, and emotionally-as they return for in-person learning. Possible solutions include the reduction from full-days to half-days in the clinical setting, and hybrid learning opportunities for didactic courses, to maintain students' ability to focus during class. Furthermore, faculty and staff should work closely with on campus resources, including counseling services and student affairs, to identify and remove barriers preventing students from seeking assistance and additional support.

\section{INNOVATIVE PRACTICES}

\section{Novel Pandemics and Public Health Threats Course for Student Retention}

As part of the School of Health Sciences' student recruitment and retention plan, a faculty member trained in health education developed and taught an eight-week online course focused on the COVID-19 pandemic. All accepted students who had committed to one of the nine undergraduate programs at the School of Health Sciences-from health sciences, exercise science, to dental hygiene-were offered the opportunity to complete the online, synchronous course at no cost and receive college credit upon successful completion. The course, titled Pandemics and Public Health Threats, challenged incoming students to think critically about the novel coronavirus pandemic of 2020 and other public health threats; it also introduced students to the fundamentals of epidemiology, public health practice, and the social determinants of health (Islam, 2019).

Pandemics and Public Health Threats proved to be successful based upon its evaluations and the low number of students who dropped the course (one student dropped due to work obligations). The course offered students an opportunity to interact with a faculty member and their future classmates in an online setting, with hopes that they (recent high school graduates) will transition into on-ground courses in the fall semester successfully. Furthermore, the course served as a key source of information regarding the ongoing COVID-19 pandemic and emerging developments (e.g., number of cases, status of vaccine development) and the safety plans at the School of Health Sciences and UNewHaven (e.g., mask mandates, social distancing, crowd control). This focus on health equity and addressing social determinants sets the foundation for students' anticipated four years at the School of Health Sciences.

Examples of positive student feedback from the course evaluations include:

I enjoyed learning about topics that I've never known to be an epidemic or that I've never really cared too much to look into.
I enjoyed speaking about our current pandemic: COVID-19! It's a new topic in which is marked in history. It amazing we are able to learn about it first in college.

Given students' positive feedback, as well as its ability to retain newly accepted students, we recommend institutions that are concerned with student retention and success to consider a similar approach in developing a special topics course. We also saw the course as an opportunity to give students' early exposure to the social determinants of health, including the role of structural racism, in shaping health outcomes and contributing to health disparities.

\section{Online Education for Clinical Lab Courses}

To meet accreditation requirements while navigating a time in which students were frequently placed into quarantine or isolation due to the pandemic, the structure of our mandatory clinical lab course for dental hygiene students had to be flexible. We received some latitude from our accrediting agencies regarding competencies as a result of the now highly restricted exposure to the surrounding patient population and partnering community clinics. We compensated for the reduction in patient contact hours by utilizing case study work, which encouraged our students to apply critical thinking skills and collaborate in teams. Additionally, faculty and staff worked diligently to secure PPE as recommended by the CDC. Keeping faculty, staff, students, and community patients safe was the priority of all clinic-based courses. Students placed into quarantine during the semester necessitated additional remote clinic course work completed online via Zoom. Despite the reduction of patient contact hours and in-class time, developing our own case studies and associated competencies allowed us to keep our students on track.

\section{DISCUSSION}

The ongoing COVID-19 pandemic has presented unprecedented challenges to institutions of higher education-our experiences at UNewHaven's School of Health Sciences were no exception. The charge of offering in-person classes, all while maintaining safety protocols to prevent the spread of COVID-19, proved to be daunting. Despite the many challenges we encountered, there were countless lessons learned, many of which we feel obligated to share with our peers at other academic institutions. Our lessons are also valuable as global leaders continue to discuss emergency preparations for future pandemics and public health threats (WHO, 2020; Robbins, 2021). Academic institutions must be prepared for such challenges. We summarize our lessons learned and recommendations in Table 2.

Based upon our experiences, we recommend colleges and universities, particularly health-related institutions (e.g., schools of health sciences) have an emergency learning plan. This plan must be flexible and adaptable to the frequently changing guidelines presented by health and government officials. Upon our return to campus during the fall 2020 semester, we learned many nontraditional spaces on campus were transformed into classrooms to accommodate social 
TABLE 2 | Summary of key challenges and recommendations.

\section{Challenges}

1. Lack of classroom space to accommodate social distancing measures

2. Reduction in clinical lab experience and patient contact hours, challenges accessing PPE

3. Effective communication

4. Emotional, mental, and physical exhaustion

4b. Feelings of disconnection

5. Student recruitment and retention

6. Unpredictable and sudden changes to state and federal guidance
Recommendations

Create and maintain non-traditional spaces on campus (e.g., university-affiliated church, athletics facilities) with technology (e.g., microphones, projectors, access to internet) as classrooms Maintain a regular supply of PPE and keep an educational plan up to date to meet alternative clinic lab requirements that adhere to accreditation standards. Consider innovative practices to accommodate the reduction in patient contact hours, such as the development and use of case studies

Equip classrooms with essential technology to ensure student and faculty success, such as microphones, cameras, internet access, projectors, computers/laptops, and other equipment Offer access to virtual services including medical counseling, mental health

counseling and virtual exercise

Prioritize opportunities for faculty, staff, and students to connect outside of the classroom Develop innovative, new courses for incoming students to ensure their successful transition into the university; the new course may also be used to educate students on campus-wide pandemic protocols (e.g., mask mandate, social distancing, quarantine and isolation requirements)

Work with local colleges, universities, and academic institutions to develop best practices and maintain a regular stream of communication. Such collaboration creates a collective cohort of institutions that can express disagreements and concerns to sudden changes to state and federal guidance distancing. We believe such measures are viable solutions but they must be equipped with adequate technology (e.g., microphones, projectors, and computers) to ensure effective teaching and learning. School officials should also ensure nontraditional classrooms be prepared to accommodate students who may be placed into quarantine or isolation and require online instruction. Students also come from diverse ability statuses and may require additional support as mask mandates and social distancing measures present challenges in hearing and engaging in classroom-based discussions. Students of lower socioeconomic statuses may also lack the financial or technological resources (e.g., laptops and tablets) to easily pivot to online learning.

The pandemic's toll on the mental health of the global community cannot be ignored. Nor can we ignore the pandemic's effects on the health-from physical, emotional, to mental-of the campus community. We noticed an increased emphasis (and understandably so) placed on protecting our community's physical health, particularly from COVID-19 infection. However, there were clear gaps in promoting and protecting the emotional and mental health of faculty, staff, and students. To ensure that on-campus instruction, including clinical and didactive courses, are achieving desired outcomes and fostering effective learning environments, academic institutions must be intentional in addressing concerns around mental and emotional health. This is a time to maximize on-campus counseling services and develop innovative strategies to cope with the heighten fear and chronic stressors.

As colleges and universities work to mitigate the negative impact of the declining number of prospective students, as well as retaining current ones, they must consider innovative practices for recruitment and retention. We found our innovative course focused on the pandemic and other public health threats helpful in recruiting and retaining students; it also served to ease the transition from high school to college as it was offered virtually at no cost in the summer leading up to fall semester. We recommend developing courses that focus on timely and appealing topics that also set the foundation for students to succeed during the duration of their time in college.

\section{CONCLUSION}

Approximately a year after the official declaration of the COVID19 pandemic, institutions of higher education continue to weigh the options in offering in-person over online courses. Regardless of their decisions, future pandemics and emerging public health threats are inevitable. Therefore, we hope our lessons learned and recommendations as faculty, staff, and students at a university that chose to offer primarily in-person courses serve as guidance to assist others who will find themselves in similar positions.

\section{DATA AVAILABILITY STATEMENT}

The original contributions presented in the study are included in the article/Supplementary Material, further inquiries can be directed to the corresponding author.

\section{AUTHOR CONTRIBUTIONS}

AT conceptualized the manuscript's focus and proposed objectives. AT and RK prepared the draft manuscript and wrote the majority of the sections. SG and SP contributed to the writing of the manuscript and provided critical revisions.

\section{ACKNOWLEDGMENTS}

The authors would like to thank the members of the University of New Haven's COVID Task Force (CTF) for their ongoing efforts to keep our campus community safe. The information CTF shared with us were also valuable in our efforts to write this manuscript. 


\section{REFERENCES}

Anderson, G. (2020). Job Security, Health Fears Make for Uneasy Mix, inside Higher, Washington, DC, United States: Inside Higher Ed. doi:10.1002/ 9781119644682

Anderton, R. S., Vitali, J., Blackmore, C., and Bakeberg, M. C. (2021). Flexible Teaching and Learning Modalities in Undergraduate Science amid the COVID19 Pandemic. Front. Education 5. doi:10.3389/feduc.2020.609703

Arens, A. K., and Morin, A. J. S. (2016). Relations between Teachers' Emotional Exhaustion and Students' Educational Outcomes. J. Educ. Psychol. 108 (6), 800-813. doi:10.1037/edu0000105

Bauman, D. (2020). The Pandemic Has Pushed Hundreds of Thousands of Workers Out of Higher Education. Washington, DC, United States: The Chronicle of Higher Education

Boehmer, T. K., DeVies, J., Caruso, E., van Santen, K. L., Tang, S., Black, C. L., et al. (2020). Changing Age Distribution of the COVID-19 Pandemic - United States, May-August 2020. MMWR Morb. Mortal. Wkly. Rep. 69 (39), 1404-1409. doi:10.15585/mmwr.mm6939e1

Budson, A. E. (2021). What Is COVID-19 Brain Fog - and How Can You clear it? Harvard Health Blog. Retrieved from Available at: https://www.health.harvard.edu/ blog/what-is-covid-19-brain-fog-and-how-can-you-clear-it-2021030822076.

Burford, B., Whittle, V., and Vance, G. H. (2014). The Relationship between Medical Student Learning Opportunities and Preparedness for Practice: a Questionnaire Study. BMC Med. Educ. 14, 223. doi:10.1186/1472-692014-223

Centers for Disease Control and Prevention (2020). Colleges \& Universities: Plan, Prepare, and Respond. Atlanta, GA, United States: U. S. Centers for Disease Control and Prevention. Retrieved from Available at: https://www.cdc.gov/ coronavirus/2019-ncov/community/colleges-universities/index.html

Centers for Disease Control and Prevention (2021). Community, Work, and School: Information for where You Live, Work, Learn, and Play. Atlanta, GA, United States: U. S. Centers for Disease Control and Prevention. Retrieved from Available at: https://www.cdc.gov/coronavirus/2019-ncov/community/ index.html

Chang, M.-L. (2009). An Appraisal Perspective of Teacher Burnout: Examining the Emotional Work of Teachers. Educ. Psychol. Rev. 21, 193-218. doi:10.1007/ s10648-009-9106-y

Goetz, T., Becker, E. S., Bieg, M., Keller, M. M., Frenzel, A. C., and Hall, N. C. (2015). The Glass Half Empty: How Emotional Exhaustion Affects the StateTrait Discrepancy in Self-Reports of Teaching Emotions. PloS one 10 (9), e0137441. doi:10.1371/journal.pone.0137441

Guadix, S. W., Sha, C., Sandrone, S., Safdieh, J. E., and Sarva, H. (2020). The Impact of COVID-19 on Neurology Education: A Medical Student Perspective. Front. Education 5. doi:10.3389/feduc.2020.567421

Here's Our List of Colleges' Reopening Models (2020). , The Chronicle of Higher Education, Washington, DC, United States: The Chronicle of Higher Education. Retrieved from Available at: https://www.chronicle. com/article/Here-s-a-List-of-Colleges-/248626?cid2=gen_login_refresh\&cid=gen_ sign_in

Higgins-Dunn, N. (2020). College Officials Say They Won't Bring Students Back to Campus This Fall without Expanded Coronavirus Testing and Tracing, CNBC, CNBC. Retrieved from Available at: https://www.cnbc.com/2020/06/04/ coronavirus-college-officials-say-they-wont-bring-students-back-to-campusthis-fall-without-expanded-testing.html

Islam, M. M. (2019). Social Determinants of Health and Related Inequalities: Confusion and Implications. Front. Public Health 7, 11. doi:10.3389/fpubh. 2019.00011

Kim, M.-K., Kim, M., Oh, E., and Kim, S.-P. (2013). A Review on the Computational Methods for Emotional State Estimation from the Human EEG. Comput. Methods Neuroengineering 2013, 1-13. doi:10.1155/2013/ 573734

Maslach, C., Schaufeli, W. B., and Leiter, M. P. (2001). Job Burnout. Annu. Rev. Psychol. 52, 397-422. doi:10.1146/annurev.psych.52.1.397
MedEd Collaborative (2020). Re-opening Universities Might Be High Risk, but it Is Essential for Medical Students. BMJ. 371, m3851. doi:10.1136/bmj.m3851

Nadworny, E. (2020). Despite Mass Testing. University of Illinois Sees CoronavirusCases Rise. NPR. Retrieved from Available at: https://www.npr. org/sections/coronavirus-live-updates/2020/09/03/909137658/university-withmodel-testing-regime-doubles-down-on-discipline-amid-case-spike

Nordhall, O., Knez, I., Saboonchi, F., and Willander, J. (2020). Teachers' Personal and Collective Work-Identity Predicts Exhaustion and Work Motivation: Mediating Roles of Psychological Job Demands and Resources. Front. Psychol. 11, 1538. doi:10.3389/fpsyg.2020.01538

Quintana, C. (2020). An Online Class by Any Other Name? College Students Pay Rent, Enroll - Then Find Courses Aren't In-Person. USA Today. doi:10.2172/ 1632676Retrieved from Available at: https:/www.usatoday.com/story/news/ education/2020/09/01/covid-college-fall-semester-online-class/5645127002/

Redden, E. (2020). CDC Issues New Testing Guidance for Colleges, inside Higher. Retrieved from Available at: https://www.insidehighered.com/news/2020/10/02/ new-cdc-guidance-gives-colleges-more-information-covid-19-testing-public-health

Robbins, J. (2021). Heading off the Next Pandemic. Kaiser Health News. doi:10. 1201/9781003042280Retrieved from Available at: https://khn.org/news/ infectious-disease-scientists-preventing-next-pandemic/

Ruegsegger, G. N., and Booth, F. W. (2018). Health Benefits of Exercise. Cold Spring Harb Perspect. Med. 8 (7), a029694. doi:10.1101/cshperspect.a029694

School of Health Sciences (2020). Retrieved from February 6, 2021 Available at: https://www.newhaven.edu/health-sciences/.

Son, C., Hegde, S., Smith, A., Wang, X., and Sasangohar, F. (2020). Effects of COVID-19 on College Students' Mental Health in the United States: Interview Survey Study. J. Med. Internet Res. 22 (9), e21279. doi:10.2196/21279

Sorrell, M. J. (2020). Colleges Are Deluding Themselves, The Atlantic. Retrieved from Available at: https://www.theatlantic.com/ideas/archive/2020/05/collegesthat-reopen-are-making-a-big-mistake/611485/

Spunt, R. P., and Adolphs, R. (2019). The Neuroscience of Understanding the Emotions of Others. Neurosci. Lett. 693, 44-48. doi:10.1016/j.neulet.2017.06.018

Taxer, J. L., Becker-Kurz, B., and Frenzel, A. C. (2019). Do quality Teacher-Student Relationships Protect Teachers from Emotional Exhaustion? the Mediating Role of Enjoyment and Anger. Soc. Psychol. Educ. 22, 209-226. doi:10.1007/ s11218-018-9468-4

Tracking the Coronavirus at U.S. Colleges and Universities (2020). The New York Times. Retrieved from Available at: https://www.nytimes.com/interactive/2020/ us/covid-college-cases-tracker.html

Treisman, R. (2020). UNC-Chapel Hill Classes to Move Online after 130 Students Test Positive in First Week, . NPR. . Retrieved from Available at: https://www. npr.org/sections/coronavirus-live-updates/2020/08/16/903071127/less-than-aweek-after-starting-classes-unc-chapel-hill-reports-4-covid-19-clust

University of New Haven (2021). West Haven, CT, United States. Retrieved Feburary 2, 2021, fromhttps://www.newhaven.edu/

WHO. (2020). The Best Time to Prevent the Next Pandemic Is Now: Countries Join Voices for Better Emergency Preparedness

Wrighton, M. S., and Lawrence, S. J. (2020). Reopening Colleges and Universities during the COVID-19 Pandemic. Ann. Intern. Med. 173 (8), 664-665. doi:10. 7326/M20-4752

Yamey, G., and Walensky, R. P. (2020). Covid-19: Re-opening Universities Is High Risk. BMJ. 370, m3365. doi:10.1136/bmj.m3365

Conflict of Interest: The authors declare that the research was conducted in the absence of any commercial or financial relationships that could be construed as a potential conflict of interest.

Copyright (c) 2021 Tran, Kerkstra, Gardocki and Papuga. This is an open-access article distributed under the terms of the Creative Commons Attribution License (CC $B Y)$. The use, distribution or reproduction in other forums is permitted, provided the original author(s) and the copyright owner(s) are credited and that the original publication in this journal is cited, in accordance with accepted academic practice. No use, distribution or reproduction is permitted which does not comply with these terms. 